Corresponding author: skingsmore@rchsd.org

(C) 2020 Kingsmore et al. This article is distributed under the terms of the Creative Commons Attribution-NonCommercial

License, which permits reuse and redistribution, except for commercial purposes, provided that the original author and source are credited.

Ontology terms: congenital horizontal nystagmus; diffuse swelling of cerebral white matter; generalized tonic seizures; hypouricemia; infantile encephalopathy; poor suck; upper limb spasticity

Published by Cold Spring Harbor Laboratory Press

doi:10.1101/mcs.a004705

\section{Mortality in a neonate with molybdenum cofactor deficiency illustrates the need for a comprehensive rapid precision medicine system}

\author{
Stephen F. Kingsmore, ${ }_{1}^{1}$ Nanda Ramchandar, ${ }^{1,2}$ Kiely James, ${ }^{1}$ Anna-Kaisa Niemi, ${ }^{2}$ \\ Annette Feigenbaum, ${ }^{2}$ Yan Ding, ${ }^{1}$ Wendy Benson, ${ }^{1}$ Charlotte Hobbs, ${ }^{1}$ \\ Shareef Nahas, ${ }^{1}$ Shimul Chowdhury, ${ }^{1}$ and David Dimmock ${ }^{1}$ \\ ${ }^{1}$ Rady Children's Institute for Genomic Medicine, San Diego, California 92123, USA; ${ }^{2}$ Department of \\ Pediatrics, Rady Children's Hospital, University of California, San Diego, California 92123, USA
}

\begin{abstract}
Neonatal encephalopathy with seizures is a presentation in which rapid whole-genome sequencing (rWGS) has shown clinical utility and improved outcomes. We report a neonate who presented on the third day of life with seizures refractory to antiepileptic medications and neurologic and computerized tomographic findings consistent with severe generalized brain swelling. rWGS revealed compound heterozygous variants in the molybdenum cofactor synthesis gene, type $1 \mathrm{~A}$ (MOCS1 c. ${ }^{* 7+5 G}>\mathrm{A}$ and c.377G > A); a provisional diagnosis of molybdenum cofactor deficiency on day of life 4 . An emergency investigational new drug application for intravenous replacement of the MOCS1 product, cyclic pyranopterin monophosphate, was considered, but felt unsuitable in light of the severity of disease and delay in the start of treatment. The patient died on day of life 9 despite having a precise molecular diagnosis within the first week of life. This case illustrates that an rWGS-based molecular diagnosis within the first week of life may be insufficient to improve outcomes. However, it did inform clinical decision-making with regard to resuscitation and predicted long-term outcome. We suggest that to achieve optimal reductions in morbidity and mortality, rWGS must be implemented within a comprehensive rapid precision medicine system (CRPM). Akin to newborn screening (NBS), CRPM will have onboarding, diagnosis, and precision medicine implementation components developed in response to patient and parental needs. Education of health-care providers in a learning model in which ongoing data analyses informs system improvement will be essential for optimal effectiveness of CRPM.
\end{abstract}

\section{INTRODUCTION}

Genetic diseases are very common among infants in intensive care units (ICUs). A recent study reported an incidence of $16 \%$ (Kingsmore et al. 2019). Genetic diseases are a leading cause of morbidity and mortality among infants in ICUs (Berry et al. 2008; Weiner et al. 2011; March of Dimes 2016; Murphy et al. 2018). Disease progression can be extremely rapid in neonates, necessitating early etiologic diagnosis and initiation of effective therapies to lessen suffering, morbidity, and mortality (Petrikin et al. 2015; Smith et al. 2015). Timely 
COLD SPRING HARBOR Molecular Case Studies
A comprehensive rapid precision medicine system diagnosis of genetic diseases requires genome-wide testing because more than 14,000 simple genetic diseases have been described and their presentations often overlap in newborns (Database of Human Structural Variants 2019; Online Mendelian Inheritance in Man 2019). Rapid whole-genome sequencing (rWGS) has demonstrated diagnostic and clinical utility in seriously ill newborns with diseases of unknown etiology in ICUs (Willig et al. 2015; Farnaes et al. 2018; Mestek-Boukhibar et al. 2018; Petrikin et al. 2018; French et al. 2019). By providing a molecular diagnosis in the first days of life, rWGS can enable timely institution of genome-informed medicine that can transform outcomes. Likewise, the absence of likely pathogenic variants in specific genes significantly reduces the likelihood of genetic disorders causing the current presentation, modifying the differential diagnosis and informing decisions regarding the appropriateness of complex interventions. Over the last 8 years, methods have been developed for increasingly rapid diagnosis of genetic diseases by rWGS, with a major focus on improved analytic and diagnostic performance (Saunders et al. 2012; Miller et al. 2015; Clark et al. 2019). Here we present a case that illustrates the need for rWGS to be implemented in routine practice within a comprehensive rapid precision medicine (CRPM) system to optimize outcomes.

\section{CASE PRESENTATION}

The patient was a Latino male infant born at $40 \mathrm{wk}$ gestation via repeat cesarean section. Apgar scores were 9 at 1 and $5 \mathrm{~min}$. He weighed $3.6 \mathrm{~kg}$ at birth (53rd percentile), with a head circumference of $34.5 \mathrm{~cm}$ (35th percentile) and length of $53.3 \mathrm{~cm}$ (79th percentile). He was discharged home after an uneventful 48-h nursery stay. Family history was significant for an older sibling who had died in Mexico at 3 days of life (DOL). The listed cause of death was sudden infant death syndrome.

Rhythmic jerking of the infant's arms and eye-rolling began on DOL 3. At a local Emergency Department, he was noted to have spastic movements of both arms and his gaze was fixed, with horizontal nystagmus. He was transferred by helicopter to Rady Children's Hospital level IV neonatal ICU. At admission, he was irritable and his arms were pronated and flexed. He had an absent suck reflex and bilateral downward eye deviation. No dysmorphic features were noted (Table 1). Initial laboratory values were within reference ranges. Computerized axial tomography of the head showed diffuse loss of gray/white matter junctions and indistinctness of cortical sulci, gyri, and boundaries of basal ganglia. Ventricles were slit-like and the Sylvian fissure was not well-delineated. Brain magnetic resonance imaging revealed severe generalized brain swelling (edema) with restricted cortical diffusion. The electroencephalogram demonstrated abundant seizures. The seizures were refractory to antiepileptic medications.

Following receipt of verbal consent, rWGS was performed on the proband and his mother on the day of admission (DOL 3). The proband genome coverage was 52 -fold and $98.2 \%$ of variants had quality scores $>40$. The proband genome had no regions of homozygosity of $>5 \mathrm{Mb}$. A low serum uric acid ( $<0.5 \mathrm{mg} / \mathrm{dL}$, reference range $2.0-7.0 \mathrm{mg} / \mathrm{dL}$ ) was reported on DOL 4. This suggested molybdenum cofactor deficiency (MOCOD), caused by biallelic pathogenic variants in either of the molybdenum cofactor synthesis genes MOCS1 or MOCS2 or in Gephyrin (GPHN) were high on the differential diagnosis. Two likely pathogenic variants (c. $* 7+5 \mathrm{G}>\mathrm{A}$ and c.377G $>$ A) were identified in MOCS1 (Table 2), which encodes two enzymes, MOCS1A and MOCS1B, in a single transcript. MOCOD is a rare inherited metabolic disorder resulting in a combined deficiency of aldehyde oxidase (EC 1.2.3.1), xanthine dehydrogenase (EC 1.1.1.204), and sulfite oxidase (EC 1.8.3.1). Most patients with MOCOD present soon after birth with intractable seizures and undetectable serum uric acid (Arenas et al. 2009). MOCS1 c. $* 7+5 G>A$ was a splice region variant, reported in the heterozygous 
Table 1. Observed and expected phenotypic features

\begin{tabular}{|c|c|}
\hline Expected phenotypes for MOCOD (OMIM ID \#252150) & Observed phenotypes \\
\hline Poor growth & Absent \\
\hline Frontal bossing & Absent \\
\hline Microcephaly & Absent \\
\hline Macrocephaly & Absent \\
\hline Long face & Absent \\
\hline Puffy cheeks & Absent \\
\hline Long philtrum & Absent \\
\hline Dislocated lenses & Absent \\
\hline Spherophakia & Absent \\
\hline Nystagmus & Present \\
\hline Elongated palpebral fissures & Absent \\
\hline Widely spaced eyes & Absent \\
\hline Small nose & Absent \\
\hline Thick lips & Absent \\
\hline Poor feeding & Present \\
\hline Asymmetric skull & Absent \\
\hline Myoclonic spasms & Present \\
\hline Absent psychomotor development & n.a. \\
\hline Intractable seizures, intractable & Present \\
\hline Opisthotonos & Absent \\
\hline Hypertonicity & Present \\
\hline Spastic quadriplegia & Absent \\
\hline Cerebral atrophy & Absent \\
\hline Thinning of the corpus callosum & Absent \\
\hline Gliosis & Absent \\
\hline Demyelination & Absent \\
\hline Axonal loss & Absent \\
\hline Cystic lysis of the deep white matter & Absent \\
\hline Enlarged ventricles & Absent \\
\hline Hypouricemia & Present \\
\hline Increased urinary xanthine & n.d. \\
\hline Increased urinary hypoxanthine & n.d. \\
\hline Increased urinary S-sulfocysteine & Present \\
\hline Increased urinary taurine & n.d. \\
\hline Xanthine stones & Absent \\
\hline Decreased xanthine dehydrogenase activity & n.d. \\
\hline Decreased sulfite oxidase activity & n.d. \\
\hline Molybdenum cofactor deficiency & n.d. \\
\hline Onset at birth & Present \\
\hline Progressive disorder & Present \\
\hline Death in childhood & Present \\
\hline
\end{tabular}

(MOCOD) Molybdenum cofactor deficiency, (n.a.) not applicable, (n.d.) not determined. 


\begin{tabular}{|c|c|c|c|c|c|c|c|c|}
\hline Gene (Transcript) & $\begin{array}{l}\text { Chromosomal variant } \\
\text { coordinate (build } 37.1 \text { ) }\end{array}$ & $\begin{array}{l}\text { HGVS DNA } \\
\text { reference }\end{array}$ & dbSNP ID & $\begin{array}{l}\text { HGVS protein } \\
\text { reference }\end{array}$ & Variant type & Genotype & Parent of origin & Classification \\
\hline $\begin{array}{l}\text { MOCS1 } \\
\quad \text { (ENSTO00000373186) }\end{array}$ & $6: 39,893,463$ & c. $377 \mathrm{G}>\mathrm{A}$ & rs372246702 & p.Gly126Asp & Missense & Heterozygous & $\begin{array}{l}\text { Unknown } \\
\quad \text { (nonmaternal) }\end{array}$ & Likely pathogenic \\
\hline $\begin{array}{l}\text { MOCS1 } \\
\quad \text { (ENST00000373186) }\end{array}$ & $6: 39,876,811$ & c. ${ }^{*} 7+5 \mathrm{G}>\mathrm{A}$ & rs752653792 & n.a. & $\begin{array}{l}\text { Splicing } \\
\quad \text { abnormality }\end{array}$ & Heterozygous & Maternal & Likely pathogenic \\
\hline
\end{tabular}

state in six of 246,238 gnomAD chromosomes (PM2). This variant was predicted to reduce splicing at the $5^{\prime}$ donor site of intron nine. Homozygous substitution of the neighboring nucleotide (c.*7 + 6T > C) in a patient with MOCOD was associated with abnormal splicing predicted to result in absence of MOCS1A (Arenas et al. 2009; Hinderhofer et al. 2017). c.*7+ $5 \mathrm{G}>\mathrm{A}$ was initially scored as a variant of uncertain significance, but after consultation with the clinical team and in light of low serum uric acid, the variant was upgraded to likely pathogenic on the basis of PM1 (proximity to $\mathrm{C} .^{*} 7+6 \mathrm{~T}>\mathrm{C}$, for which functional studies showed aberrant splicing [Arenas et al. 2009], together with high level of conservation and similar splice effects predicted in c.*7 + 6T > C), PM2, PP3 (NNSplice v0.9: -0.575 [predicted to weaken the more $3^{\prime}$ donor site at c.*7+1], GeneSplicer $=-1.987$ [predicted to weaken the more $3^{\prime}$ donor site at c. ${ }^{* 7+1}$ ], MaxEntScan $=-9.282$ [(predicted to weaken the more $3^{\prime}$ donor site at c.*7 + 1]), and PP4 (Richards et al. 2015). MOCS1 c.377G >A has been previously reported in a patient with MOCOD (Arenas et al. 2009; Hinderhofer et al. 2017) (PM3) and was also rare (heterozygous in 14 of 245,472 gnomAD chromosomes, PM2). It was scored as likely pathogenic on the basis of PM3 (in trans with c.418+1G $>A$ in Hinderhofer et al. 2017), PM2, PP3 (Mutation Taster: 1, PolyPhen-2_HDIV (v2.2.2): 0.997, SIFT: 0), and PP4 (Richards et al. 2015). No other diagnostic variants were found in other genes. A provisional diagnosis of MOCOD was reported to the NICU team in $34 \mathrm{~h}$ (DOL 4). The diagnosis was confirmed on DOL 9 by elevated urinary S-sulfocysteine $(731 \mathrm{\mu mol} /$ $\mathrm{g}$ creatinine, reference range $\leq 80 \mu \mathrm{mol} / \mathrm{g}$ creatinine; ordered on DOL 3 ).

MOCS1 catalyzes the production of cyclic pyranopterin monophosphate (cPMP), the first step in the synthesis of molybdenum cofactor (Schwahn et al. 2015). Daily intravenous replacement of cPMP restores molybdenum cofactor-dependent enzyme activities (Schwahn et al. 2015). If replacement is started before onset of encephalopathy, long-term developmental outcomes are good (Schwahn et al. 2015). Subsequent treatment may alleviate symptoms. Unfortunately, 15 years after the first infant with MOCOD benefitted from CPMP (Schwarz et al. 2004), and despite the FDA "breakthrough therapy" designation in 2013, cPMP remains an experimental therapy and no clinical trials are currently enrolling neonates. Commercial rights to cPMP have been transferred at least three times, most recently to Origin Biosciences in 2016. A single-patient Emergency Investigational New Drug (eIND) application was considered in our neonate. However, in light of the severity of disease and anticipated delay of days to weeks in commencing treatment, he was not considered a suitable candidate. On DOL 9, he became apneic and severely bradycardic. Despite aggressive resuscitation, he continued to decline clinically, developing severe lactic acidosis in the setting of poor cardiac function and respiratory failure. Care was redirected and the patient died of his underlying disease.

\section{DISCUSSION}

MOCOD is a prototypic example of a very rare genetic disorder whose outcome may be changed by prompt diagnosis and treatment. The onset of symptoms in MOCOD occurs 
typically on the first day of life with seizures (Mechler et al. 2015). In the absence of rapid genomic sequencing, the median age at diagnosis is $4.5 \mathrm{mo}$ (Mechler et al. 2015). Here, diagnosis was made on the fourth day of life, a day after clinical and imaging evidence of severe brain damage. As a result, the decision was made not to proceed with cPMP therapy. Regrettably, the infant's sibling likely died of the same condition. Had a molecular diagnosis been made in that sibling, fetal or perinatal diagnosis would have been possible in the proband, enabling early delivery by cesarean section, replacement of cPMP at birth, and early institution of supportive care. MOCOD is frequently misdiagnosed as hypoxic-ischemic encephalopathy or cerebral palsy (Topcu et al. 2001; Kikuchi et al. 2012; Zahid et al. 2019).

This case powerfully illustrates rWGS that provides a molecular diagnosis within the first week of life may be insufficient to improve outcomes. In neonatal encephalopathy, even if rWGS is ordered promptly and performed rapidly in the context of a regional ICU with a full complement of pediatric subspecialists experienced in newborn genomic medicine, a molecular diagnosis may be made too late to improve outcomes. To decrease newborn morbidity and mortality optimally, we suggest that rWGS must be implemented within a comprehensive system for rapid delivery of precision medicine (CRPM) (Stark et al. 2018; Pearce et al. 2019). As rWGS gains broader use in infants in ICUs worldwide, such a CRPM system will be particularly needed in hospitals lacking the full complement of pediatric subspecialists, including neurologists or medical geneticists experienced in CRPM.

National systems of newborn screening (NBS) of healthy neonates for 30 to 50 genetic disorders that have very early progression and effective treatments have reduced their morbidity and mortality (Berry 2015; Therrell et al. 2015). Upon approval of cPMP, MOCOD may be suitable for inclusion in genomic-based NBS or expanded carrier screening programs. The pretest probability of genetic diseases in seriously ill neonates in ICUs with diseases of unknown etiology is about 10,000-fold greater than in healthy infants receiving NBS (Kingsmore et al. 2019). Nevertheless, the components of an effective CRPM system would be rather similar to those of NBS (Fig. 1; Therrell et al. 2010), including the following.

1. Iterative development and administration of payer-specific, state and national policies are needed to (a) define indications for rWGS; (b) evaluate the robustness of evidence of efficacy for individual genetic disease treatments; (c) establish quality metrics to improve CRPM performance; and (d) require insurance authorization for reimbursement. Because such policies will be developed incrementally over several years for thousands of conditions there is an interim need for pioneering regional hospitals to establish centers of excellence in CRPM. This was the rationale behind the Vermont Oxford Rady Children's Genomic Network (https://publicvtoxfordorg/genomicnetwork).

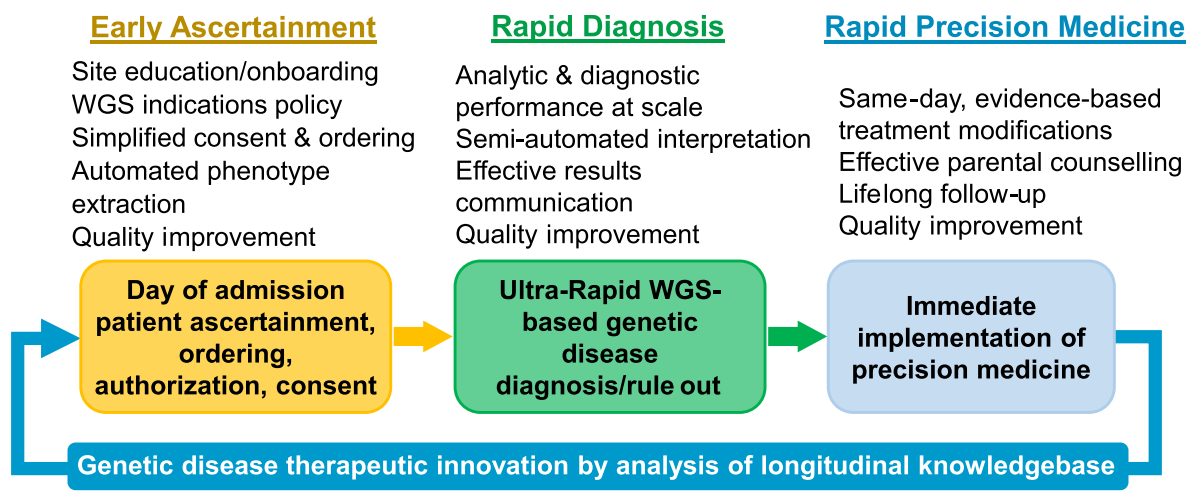

Figure 1. Components of the proposed comprehensive system for delivery of newborn precision medicine. 
COLD SPRING HARBOR Molecular Case Studies
A comprehensive rapid precision medicine system
2. Ascertainment encompasses (1) rapid ascertainment of newborns who may benefit from CRPM; (2) education and equipping of providers to obtain informed consent and explain scope of interpretation; (3) creation of rWGS order sets in electronic health records (EHRs); (4) rapid authorization of rWGS; (5) rapid blood sample collection and shipment; (6) communication of sufficient details of the phenotype and near-term clinical decisionmaking to facilitate diagnosis with appropriate time to result. Hitherto, rWGS-based CRPM has largely been limited to research studies with clear inclusion/exclusion criteria and dedicated program managers and enrollment and genetic counseling personnel. Ascertainment activities require iterative development, provider education, and onboarding. In the current case, ascertainment was seamless. However, in general we have found the switch from funded research rWGS to prior authorization of commercial testing to be not straightforward and that it required peer-to-peer communication and education of providers and payers. Ascertainment activities must be specific, contextually sensitive, semiautomated, and integrated into the EHRs. For example, we developed an rWGS ordering portal that was linked to the EHRs and interpretation software portal to facilitate ascertainment activities (Clark et al. 2019). We have also implemented quality assessment to measure the proportion of suitable infants in whom rWGS is performed, time to test order, and rate of prior authorization.

3. Early diagnosis encompasses sample receipt through reporting of preliminary and final results. In the current case, a provisional diagnosis of MOCOD was reported in $34 \mathrm{~h}$. Although time from sample receipt to provision of preliminary results can be as short as $19 \mathrm{~h}$ (Clark et al. 2019), further automation is needed to achieve this in routine clinical practice. Standards for analytic and diagnostic performance and variant interpretation of genomic sequencing reflect consequences for gene function but do not currently consider the clinical context (Rehm et al. 2013; Aziz et al. 2015; Richards et al. 2015; Matthijs et al. 2016; Roy et al. 2018). In the context of acutely ill infants in ICUs with diseases of unknown etiology, the pretest probability of an underpinning genetic disease is high and, absent CRPM, morbidity and mortality are extreme, as exemplified in the current case. Specific, contextually congruous standards are needed for classification of likelihood of molecular diagnosis in this population. For acutely ill infants in ICUs, the goodness of fit of observed phenotypes to those of newborn diseases suggested by genomic variants, presence of pathognomonic features, availability of timely confirmatory diagnostic studies, and the risk/benefit ratio of immediate treatment for the associated disorder should also be important determinants of likelihood of a molecular diagnosis. An example has been proposed by the European Society for Human Genetics (https:// wwweshgorg/fileadmin/wwweshgorg/documents/Variant_classification_system/Variant_ class_ESHGpdf). In the current case, the classification of the pathogenicity of MOCS1 c.*7 $+5 G>$ A was not straightforward. For optimal effectiveness in NICUs, rWGS reports must be communicated in a manner that is comprehensible to ICU teams. Effective communication requires some molecular genetic education of NICU teams, deobfuscation of verbal and written reports, and individualized guidance about certainty of specific diagnoses (akin to ACT sheets in NBS) (ACMG ACT sheets 2019). Finally, the diagnostic phase should be subject to a quality improvement cycle to ensure continuous enhancement of analytic and diagnostic performance, including the time to reporting and effectiveness of communication of results.

4. Precision medicine encompasses clear communication to parents, genetic counseling, and both immediate and lifelong, genome-informed modification of treatment. Although there are more than 14,000 genetic diseases, only 725 currently have published management guidelines (Adam et al. 2019). As in the current case, treatments may not be FDA-approved. Many genetic disease treatments have either not been subject to clinical 
COLD SPRING HARBOR Molecular Case Studies
A comprehensive rapid precision medicine system trials or evidence of efficacy and effectiveness is limited to case reports or small case series. Furthermore, the prognosis and complications of many genetic diseases are not well understood or are highly variable. Thus, there exists an immense need to integrate evidence of therapeutic efficacy and to provide high-quality clinical decision support to ICU teams for rare genetic diseases. Where treatments are not readily available, as herein, there exists the need for CRPM to include support services, such as expert navigation and preparation of eIND applications and reports (https://wwwfdagov/drugs/ investigational-new-drug-ind-application/emergency-ind-timeline). Not infrequently, newborns will have been discharged before the return of results. Because neonatology is an inpatient specialty, the postanalytic components, as with NBS, must routinely include follow-up, frequently for medically complex patients. Akin to NBS, treatment is often lifelong. Finally, as with the other components, there exist substantial needs both to educate health-care providers and to assess quality, with goals related to parental understanding of results, their satisfaction with care, clinical utility of results, and long-term outcomes.

Finally, the data generated for each case should be collected in a knowledgebase for ongoing system performance assessment and revision of NBM policy. In time, as individual genetic diseases are recurrently diagnosed, that knowledgebase will become a powerful resource for improvement of interpretation, genetic counseling, and treatment (Chambers et al. 2016).

\section{METHODS}

Following receipt of verbal consent, rWGS was performed on the proband and his mother on the day of admission at our California-licensed, Clinical Laboratory Improvement Amendments (CLIA)-certified and College of American pathologists (CAP)-accredited laboratory as previously described (Clark et al. 2019). Following DNA extraction from whole blood, sequencing libraries were constructed using the TruSeqDNA PCR-Free Library Prep kit (Illumina) according to the manufacturer's instructions. Paired-end sequencing was performed on a NovaSeq 6000 and S1 flowcell (Illumina) (Table 3). The DRAGEN processor (Illumina) was used for rapid alignment and nucleotide variant calling (Table 3 ). The proband genome had no regions of homozygosity of $>5 \mathrm{Mb}$. Variant analysis and interpretation were performed using the Clinical Reporter (Fabric Genomics, version 6.4.1). Variants affecting splicing were predicted by MaxEntScan, NNSPLICE, and GeneSplicer (Reese et al. 1997; Pertea et al. 2001; Yeo and Burge 2004). Human Phenotype Ontology terms used at interpretation were seizures (HP:0001250) and lactic acidosis (HP:0003128). Variants were filtered to retain those with allele frequencies of $<0.5 \%$ in population databases, and classified

\begin{tabular}{lc}
\hline Table 3. Proband genome sequencing metrics & Value \\
\hline Metric & $2 \times 100 \mathrm{nt}$ \\
\hline Read length & $52-f \circ l d$ \\
Mean coverage & $4,829,581$ \\
Nucleotide variants identified & $98.2 \%$ \\
Variants with quality scores $>40$ & 26,202 \\
Coding nucleotide variants identified and & 0.59 \\
Homozygous: heterozygous ratio of coding nucleotide variants & 2.88 \\
Transition to transversion ratio of coding nucleotide variants & \\
\hline
\end{tabular}


C OLD SPRING HARBOR Molecular Case Studies
A comprehensive rapid precision medicine system
Competing Interest Statement

The authors have declared no competing interest.

Received August 14, 2019; accepted in revised form October 30, 2019 according to American College of Medical Genetics and Genomics (ACMG)/Association of Molecular Pathology (AMP) guidelines. The likely causative variants were orthogonally confirmed by PCR and Sanger sequencing.

\section{ADDITIONAL INFORMATION}

\section{Data Deposition and Access}

Sequencing data is not publicly available because this was a quality improvement project with Institutional Review Board waiver. Thus, informed written consent to share sequencing data was not obtained. The ClinVar (https://www.ncbi.nlm.nih.gov/clinvar/) accession numbers for c. ${ }^{* 7+5 G}>A$ and c.377G $>A$ are VCV000692068.1 and VCV000692063.1, respectively.

\section{Ethics Statement}

Clinical rWGS was performed as part of Project Baby Bear, a Medi-Cal quality improvement project funded by the California Department of Health Care Services. Verbal consent for mother-infant duo rWGS was obtained. The Institutional Review Board of Rady Children's Hospital, San Diego, and University of California-San Diego issued a waiver for Project Baby Bear.

\section{Acknowledgments}

We thank Dr. Antonie Meixel, who provided excellent care for this infant.

\section{Author Contributions}

S.F.K. wrote the manuscript. All authors reviewed the final version. N.R., A.F., K.J., and A.-K.N. performed chart review and wrote the clinical presentation. K.J., S.N., and S.C. performed variant interpretation. Y.D. supervised laboratory operations. D.D. provided genomic medicine guidance. W.B., C.H., D.D., and S.F.K. developed the strategy for CRPM.

\section{Funding}

rWGS was performed as part of a Medi-Cal quality improvement project funded by the California Department of Health Care Services in accordance with Senate Bill 840 (Project Baby Bear).

\section{REFERENCES}

Adam MP, Ardinger HH, Pagon RA, Wallace SE, Bean LJH, Stephens K, Amemiya A. 2019. GeneReviews ${ }^{\circledR}$. University of Washington, Seattle.

American College of Medical Genetics ACT Sheets and Confirmatory Algorithms. 2019. https:// www.ncbi.nlm .nih.gov/books/NBK55832/

Arenas M, Fairbanks LD, Vijayakumar K, Carr L, Escuredo E, Marinaki AM. 2009. An unusual genetic variant in the MOCS1 gene leads to complete missplicing of an alternatively spliced exon in a patient with molybdenum cofactor deficiency. J Inherit Metab Dis 32: 560-569. doi:10.1007/s10545-009-1151-7

Aziz N, Zhao Q, Bry L, Driscoll DK, Funke B, Gibson JS, Grody WW, Hegde MR, Hoeltge GA, Leonard DG, et al. 2015. College of American Pathologists' laboratory standards for next-generation sequencing clinical tests. Arch Pathol Lab Med 139: 481-493. doi:10.5858/arpa.2014-0250-CP

Berry MA, Shah PS, Brouillette RT, Hellmann J. 2008. Predictors of mortality and length of stay for neonates admitted to children's hospital neonatal intensive care units. J Perinatol 28: 297-302. doi:10.1038/sj.jp .7211904

Berry SA. 2015. Newborn screening. Clin Perinatol 42: 441-453. doi:10.1016/j.clp.2015.03.002 
Chambers DA, Feero WG, Khoury MJ. 2016. Convergence of implementation science, precision medicine, and the learning health care system: a new model for biomedical research. J Am Med Assoc 315: 19411942. doi:10.1001/jama.2016.3867

Clark MM, Hildreth A, Batalov S, Ding Y, Chowdhury S, Watkins K, Ellsworth K, Camp B, Kint Cl, Yacoubian C, et al. 2019. Diagnosis of genetic diseases in seriously ill children by rapid whole-genome sequencing and automated phenotyping and interpretation. Sci Transl Med 11: eaat6177. doi:10.1126/scitranslmed .aat6177

Database of Human Structural Variants dbVar. 2019. https://wwwncbinlmnihgov/dbvar?term=\%22clin\% 20pathogenic\%22\%5BFilter\%5D.\%20AND\%20homo\%20sapiens\%5BOrganism\%5D

Farnaes L, Hildreth A, Sweeney NM, Clark MM, Chowdhury S, Nahas S, Cakici JA, Benson W, Kaplan RH, Kronick R, et al. 2018. Rapid whole-genome sequencing decreases infant morbidity and cost of hospitalization. NPJ Genom Med 3: 10. doi:10.1038/s41525-018-0049-4

French CE, Delon I, Dolling H, Sanchis-Juan A, Shamardina O, Mégy K, Abbs S, Austin T, Bowdin S, Branco RG, et al. 2019. Whole genome sequencing reveals that genetic conditions are frequent in intensively ill children. Intensive Care Med 45: 627-636. doi:10.1007/s00134-019-05552-x

Hinderhofer K, Mechler K, Hoffmann GF, Lampert A, Mountford WK, Ries M. 2017. Critical appraisal of genotype assessment in molybdenum cofactor deficiency. Inherit Metab Dis 40: 801-811. doi:10.1007/s10545017-0077-8

Kikuchi K, Hamano S, Mochizuki H, Ichida K, Ida H. 2012. Molybdenum cofactor deficiency mimics cerebral palsy: differentiating factors for diagnosis. Pediatr Neurol 47: 147-149. doi:10.1016/j.pediatrneurol .2012.04.013

Kingsmore SF, Cakici JA, Clark MM, Gaughran M, Feddock M, Batalov S, Bainbridge MN, Carroll J, Caylor SA, Clarke C, et al. 2019. NSIGHT2: a randomized, controlled trial of the analytic and diagnostic performance of singleton and trio, rapid genome and exome sequencing in seriously ill infants. AJHG 105: 719-733. doi:10.1016/j.ajhg.2019.08.009

March of Dimes. 2016. The March of Dimes data book for policy makers: maternal, infant and child health in the United States 2016. http://wwwmarchofdimesorg/March-of-Dimes-2016-Databookpdf

Matthijs G, Souche E, Alders M, Corveleyn A, Eck S, Feenstra I, Race V, Sistermans E, Sturm M, Weiss M, et al. 2016. Guidelines for diagnostic next-generation sequencing. Eur J Hum Genet 24: 2-5. doi:10.1038/ejhg .2016 .63

Mechler K, Mountford WK, Hoffmann GF, Ries M. 2015. Ultra-orphan diseases: a quantitative analysis of the natural history of molybdenum cofactor deficiency. Genet Med 17: 965-970. doi:10.1038/gim.2015.12

Mestek-Boukhibar L, Clement E, Jones WD, Drury S, Ocaka L, Gagunashvili A, Le Quesne Stabej P, Bacchelli C, Jani N, Rahman S, et al. 2018. Rapid paediatric sequencing RaPS: comprehensive real-life workflow for rapid diagnosis of critically ill children. J Med Genet 55: 721-728. doi:10.1136/jmedgenet-2018-105396

Miller NA, Farrow EG, Gibson M, Willig LK, Twist G, Yoo B, Marrs T, Corder S, Krivohlavek L, Walter A, et al. 2015. A 26-hour system of highly sensitive whole genome sequencing for emergency management of genetic diseases. Genome Med 7: 100. doi:10.1186/s13073-015-0221-8

Murphy SL, Xu J, Kochanek KD, Arias E. 2018. Mortality in the United States, 2017. NCHS Data Brief. https ://wwwncbin/mnihgov/pubmed/30500322

Online Mendelian Inheritance in Man. 2019. https://wwwomimorg/statistics/geneMap

Pearce C, Goettke E, Hallowell N, McCormack P, Flinter F, McKevitt C. 2019. Delivering genomic medicine in the United Kingdom National Health Service: a systematic review and narrative synthesis. Genet Med doi:10.1038/s41436-019-0579-x

Pertea M, Lin X, Salzberg SL. 2001. GeneSplicer: a new computational method for splice site prediction. Nucleic Acids Res 29: 1185-1190. doi:10.1093/nar/29.5.1185

Petrikin JE, Willig LK, Smith LD, Kingsmore SF. 2015. Rapid whole genome sequencing and precision neonatology. Semin Perinatol 39: 623-631. doi:10.1053/j.semperi.2015.09.009

Petrikin JE, Cakici JA, Clark MM, Willig LK, Sweeney NM, Farrow EG, Saunders CJ, Thiffault I, Miller NA, Zellmer L, et al. 2018. The NSIGHT1-randomized controlled trial: rapid whole-genome sequencing for accelerated etiologic diagnosis in critically ill infants. NPJ Genom Med 3: 6. doi:10.1038/s41525-018-0045-8

Reese MG, Eeckman FH, Kulp D, Haussler D. 1997. Improved splice site detection in genie. J Comp Biol 4: 311-323. doi:10.1089/cmb.1997.4.311

Rehm HL, Bale SJ, Bayrak-Toydemir P, Berg JS, Brown KK, Deignan JL, Friez MJ, Funke BH, Hegde MR, Lyon E. 2013. American College of Medical Genetics and Genomics clinical laboratory standards for next-generation sequencing. Genet Med 15: 733-747. doi:10.1038/gim.2013.92

Richards S, Aziz N, Bale S, Bick D, Das S, Gastier-Foster J, Grody WW, Hegde M, Lyon E, Spector E, et al. 2015. Standards and guidelines for the interpretation of sequence variants: a joint consensus recommendation of the American College of Medical Genetics and Genomics and the Association for Molecular Pathology. Genet Med 17: 405-424. doi:10.1038/gim.2015.30 
Roy S, Coldren C, Karunamurthy A, Kip NS, Klee EW, Lincoln SE, Leon A, Pullambhatla M, Temple-Smolkin RL, Voelkerding KV, et al. 2018. Standards and guidelines for validating next-generation sequencing bioinformatics pipelines: a joint recommendation of the Association for Molecular Pathology and the College of American Pathologists. J Mol Diagn 20: 4-27. doi:10.1016/j.jmoldx.2017.11.003

Saunders CJ, Miller NA, Soden SE, Dinwiddie DL, Noll A, Alnadi NA, Andraws N, Patterson ML, Krivohlavek LA, Fellis J, et al. 2012. Rapid whole-genome sequencing for genetic disease diagnosis in neonatal intensive care units. Sci Transl Med 4: 154ra135. doi:10.1126/scitranslmed.3004041

Schwahn BC, Van Spronsen FJ, Belaidi AA, Bowhay S, Christodoulou J, Derks TG, Hennermann JB, Jameson E, König K, McGregor TL, et al. 2015. Efficacy and safety of cyclic pyranopterin monophosphate substitution in severe molybdenum cofactor deficiency type A: a prospective cohort study. Lancet 386: 1955-1963. doi:10.1016/S0140-6736(15)00124-5

Schwarz G, Santamaria-Araujo JA, Wolf S, Lee HJ, Adham IM, Gröne HJ, Schwegler H, Sass JO, Otte T, Hänzelmann $P$, et al. 2004. Rescue of lethal molybdenum cofactor deficiency by a biosynthetic precursor from Escherichia coli. Hum Mol Genet 13: 1249-1255. doi:10.1093/hmg/ddh136

Smith LD, Willig LK, Kingsmore SF. 2015. Whole-exome sequencing and whole-genome sequencing in critically ill neonates suspected to have single-gene disorders. Cold Spring Harb Perspect Med 6: a023168. doi:10.1101/cshperspect.a023168

Stark Z, Lunke S, Brett GR, Tan NB, Stapleton R, Kumble S, Yeung A, Phelan DG, Chong B, Fanjul-Fernandez $M$, et al. 2018. Meeting the challenges of implementing rapid genomic testing in acute pediatric care. Genet Med 20: 1554-1563. doi:10.1038/gim.2018.37

Therrell BL Jr, Schwartz M, Southard C, Williams D, Hannon WH, Mann MY, PEAS Organizing and Working Groups. 2010. Newborn screening system performance evaluation assessment scheme PEAS. Semin Perinatol 34: 105-120. doi:10.1053/j.semperi.2009.12.002

Therrell BL, Padilla CD, Loeber JG, Kneisser I, Saadallah A, Borrajo GJ, Adams J. 2015. Current status of newborn screening worldwide: 2015. Semin Perinatol 39: 171-187. doi:10.1053/j.semperi.2015.03.002

Topcu M, Coskun T, Haliloglu G, Saatci I. 2001. Molybdenum cofactor deficiency: report of three cases presenting as hypoxic-ischemic encephalopathy. J Child Neurol 16: 264-270. doi:10.1177/088307380 101600406

Weiner J, Sharma J, Lantos J, Kilbride H. 2011. How infants die in the neonatal intensive care unit: trends from 1999 through 2008. 2011. Arch Pediatr Adolesc Med 165: 630-634. doi:10.1001/archpediatrics.2011.102

Willig LK, Petrikin JE, Smith LD, Saunders CJ, Thiffault I, Miller NA, Soden SE, Cakici JA, Herd SM, Twist G, et al. 2015. Whole-genome sequencing for identification of Mendelian disorders in critically ill infants: a retrospective analysis of diagnostic and clinical findings. Lancet Respir Med 3: 377-387. doi:10.1016/ S2213-2600(15)00139-3

Yeo G, Burge CB. 2004. Maximum entropy modeling of short sequence motifs with applications to RNA splicing signals. J Comput Biol 11: 377-394. doi:10.1089/1066527041410418

Zahid M, Khan AH, Yunus ZM, Chen BC, Steinmann B, Johannes H, Afroze B. 2019. Inherited metabolic disorders presenting as hypoxic ischaemic encephalopathy: a case series of patients presenting at a tertiary care hospital in Pakistan. J Pak Med Assoc 69: 432-436. 


\section{COLD SPRING HARBOR Molecular Case Studies}

\section{Mortality in a neonate with molybdenum cofactor deficiency illustrates the need for a comprehensive rapid precision medicine system}

Stephen F. Kingsmore, Nanda Ramchandar, Kiely James, et al.

Cold Spring Harb Mol Case Stud 2020, 6: a004705

Access the most recent version at doi: $10.1101 / \mathrm{mcs} . a 004705$

References This article cites 35 articles, 4 of which can be accessed free at:

http://molecularcasestudies.cshlp.org/content/6/1/a004705.full.html\#ref-list-1

License This article is distributed under the terms of the Creative Commons

Attribution-NonCommercial License, which permits reuse and redistribution, except for commercial purposes, provided that the original author and source are credited.

Email Alerting Receive free email alerts when new articles cite this article - sign up in the box at the Service top right corner of the article or click here. 